\title{
An IT Approach to Improve the Compilation of Clinical Access Indicators and Disease Prevalence Determination for District Health Administrators
}

\section{The Case of East Mamprusi District Directorate of Ghana Health Service}

\author{
Zakaria Abukari \\ School of Applied Science \\ Dept. of Computer Science \\ Tamale Polytechnic \\ Tamale, Ghana
}

\author{
Abeo Timothy Apasiba \\ School of Applied Science \\ Dept. of Computer Science \\ Tamale Polytechnic \\ Tamale, Ghana
}

\author{
George Abraham \\ District Director \\ Ghana Health Services \\ Tatale-Sanguli District \\ Tatale, Ghana
}

\begin{abstract}
The proportion of persons visiting a health facility reflects the level of access of that centre to its catchment area in terms of Out-Patient Department (OPD) per capita. These attendances come with diagnoses which give an indication of the diseases pattern and prevalence within the catchment area as well as patients who are insured and not insured. Though data of this nature are undisputedly crucial to public health processes, morbidity returns from most health facilities, particularly public health facilities are generated manually making it cumbersome and stressful. In addition, this method is error-prone and as such poses a strong threat to disease prevention, control and information management. This research therefore uses an Information Technology approach to improve the process achieving over $90 \%$ time gain. The Gambaga Health Centre in the East Mamprusi District was selected for the simulation.
\end{abstract}

Keywords: OPD; Morbidity; Database; Clinic; Health Information system; Health Metrics Network

\section{INTRODUCTION}

Health care is an information intensive industry in which reliable and timely information is a critical resource for the planning and monitoring of service provision at all levels of analysis be it organizational, regional, national and international (Paolo, Nicola, Luca, \& Mariano). As a consequence, Information and Communication Technologies (ICTs) have become enabler in the health care sector. Healthcare institutions are not excluded in the use of advance technologies derived from the proliferation of the silicon chip for record keeping. The records kept include patients' attendances, diagnoses, treatments, health insurance etc. These records are used by the Public Health Units for planning, controlling and preventing diseases.

The Ghana Health Service together with its partners and other health agencies are responsible for the provision of health care delivery to the people of Ghana. This involves the planning, implementation, monitoring and performance assessment of health programmes and services (Ghana Health Service, 2010). In order to fulfil this role, there is the need for accurate, relevant and timely information on the health status and health services in Ghana (Ghana Health Service, 2010). Well-kept patient data also assists healthcare managers in determining how much resources are needed to manage such occurrences.

Over the past decades, information systems have played crucial roles in the development process of most of the advance World
(Erickson, 2002). According to (Gregor \& Jones, 2006) information systems are said to be the wheels on which steady and sustainable development strives. The United States of America, Germany, China and most of the countries with modern health care systems are advancing daily because of current technological development (Gregor \& Jones, 2006).

The health sector in Ghana is facing the challenges of adequately sourcing and keeping information on what pertains in the sector just because the systems that are supposed to be put in place for such information retention are in small scale if not lacking. This situation is even worse at the rural-urban health centres. Government and policy makers have emphasized the importance of computer-base information systems (CBIS) noting that achieving universal access to quality health care is highly dependent on modern health information systems (Andries \& Bob, 2008).

The National Health Insurance since its introduction has led to increases in utilization of OPD services across all the regions. With these increases, there has not been equally significant improvement in infrastructure of most of the facilities to accommodate this phenomenon (Ministry of Health, 2013).

According to a Health Metrics Network (HMN) assessment report of Ghana's health information system (DHIMS), there is an urgent need for major improvements in the way the nation's health system collects and uses data (Ministry of Health, 2006). 
The use of modern systems of communication, data storage and retrieval at all levels or facet of society especially the Ghana Health Services through the use of computers is being emphasized (Hall, 2003)

It is against these backgrounds that this research realization became preponderant to provide a rudimentary solution to accurate data compilations at the OPDs of the source health facilities. The wise men say that "a thousand-mile journey begins with the first step".

The study is limited to the East Mamprusi District in the Northern Region of Ghana. The scope further focused on the Out-Patient Department, Public Health Unit and as well as a random sampling and interviewing of some clinical and records staff of the Gambaga Health Centre and others from the East Mamprusi District Health Administration

\section{STATEMENT OF THE PROBLEM}

At the end of every month, the patient attendance books are taken from the consulting rooms for manual generation of morbidity and OPD returns reports by the Public Health Unit of the Health facilities. These reports are then forwarded to the District and Regional Health Directorates for actions. Normally, diseases and persons are grouped by sex, age, NHIS (National Health Insurance Scheme) insured and not insured. Whilst the morbidity report gives the breakdown of the disease, taking into consideration that some clients may have co-morbidity, the OPD statement gives a breakdown of persons who attend the facility within the reporting period. The compilation of the OPD and the morbidity reports are currently done manually which never yields the desired results for the Ghana Health Service (GHS). Major problems of the manual compilations included:

i. Time consuming exercise

ii. During the period of compilation, the consulting rooms' registers are not available for further entries i.e. if the compilation takes a week, then consultation entries for that week will not be recorded and thus will not reflect in that months reports.

iii. In some cases the OPD is more than the morbidity which is logically impossible since the OPD report counts individuals whilst the morbidity counts diagnoses presented by each patient.

In the light of these challenges and considering the crucial importance of the morbidity and OPD returns to the Public Health Processes in the GHS, this research comes in to solve the problem using a state of the art Information Technology tools.

\section{OBJECTIVES OF THE STUDY}

This work seeks to examine the feasibility and implementation of Health Information Systems technology in the compilation of the clinical access indicators contained in the OPD and morbidity reports which are monthly generated in all public health centres in the country. The specific objectives include:

i. Conduct an in-depth research exploration on Health Information Systems in Ghana with emphasis on OPD and Morbidity reports compilation in the public health sector

ii. Develop a working software solution of the OPD and morbidity reports compilation for implementation in the East Mamprusi District.

iii. Showcase the robustness of ICTs for effective information processing, storage and retrieval in the Public Health Units of the GHS.

\section{SIGNIFICANCE OF THE STUDY}

The significance and relevance of this research to the Public Health Units of the GHS are numerous. These include but not limited to:

i. Time spent in generating the OPD and morbidity reports will be reduced to a few button clicks giving the health workers more time to attend to other issues.

ii. The generated reports will be accurate, reliable and timely for district and regional health directorates.

iii. The Health Administrators in the East Mamprusi District for the first time can lay hands on timely and accurate morbidity reports leading to better health care planning, improved diagnosis, disease control, prevention and eradication in its catchment area.

iv. Pave way for the creation and adoption of IT enabled services in other functional units in the public health centres.

v. The research report shall constitute an academic reference to other researchers in the subject matter.

\section{METHODOLOGY}

Two principal research techniques were adopted. Initially, a variety of formal and informal participatory methods were used to obtain the background information needed to constructively carryout the study. The informal methods involved observation, the use of key informants and in-depth interviews of key stakeholders whilst the formal methods included the use of Public Health Nurses to manually compile OPD and morbidity reports for thirty(30) clients on sampled attendances for quantitative and qualitative analyses of the compilation processes. The next technique was an extensive literature reviews on HIS and its initiatives in the GHS to have a comprehensive view of the problem and its solution to be piloted at the Gambaga Health Centre.

\section{LITERATURE REVIEW}

Various literatures on the thematic areas of the research have been reviewed. Clinical Access Indicators and their compilation in the GHS were first looked at. The researched targeted a problem base solution, and for that reason, technologies and methodologies for developing functional health information systems such as database management systems, systems analyses and design with emphasis on the traditional software development life cycle and the choice of either desktop application or web based software were rigorously studied as the major theoretical underpinning. In order to pilot the solution, the review culminated in the analyses of the ICT status in the Gambaga Health Centre to help focus on implementable information system based on available resources. 


\subsection{Clinical Access in Ghana}

There are many factors that influence access to clinical and health services in Ghana. Access to clinical services is defined as living within thirty (30) minutes to any kind of modern health facility. It is also stated that access to health care services indicates the degree to which individuals are inhibited in their ability to gain entry to and receive care and services from the health care system (Ministry of Health, 1996). Geographical, financial, level of education, availability of health facilities, health professionals, transportation etc. are all factors which influence access to health care. Geographical access indicates the spatial interaction of people and health facilities. Financial access refers to the ability of the people to demand and pay for health services when the need arises. The level of an individual's education affects his/her access to health services. Most illiterates have beliefs and myths that make them belief that modern health care poses problems to them hence they do not access the facilities (Ministry of Health, 2006). A Core Welfare Indicator survey conducted by the Ghana Statistical Services (GSS) in 2003 indicated that between 1997 and 2003, the percentage of people stating that they had access to a health facility increased from $37 \%$ to $58 \%$ (GSS, 2003).

The 2004 Ghana Demographic and Health Survey (GDHS) gave the following health status indicators: infant mortality rate: 68 per 1000 live births; under 5 mortality rate: 112 per 1000 live births; maternal mortality: 540 per 100,000 live births and life expectancy: 57.2 years. Malaria remains the most frequently reported cause of morbidity and a major cause of childhood mortality. Other frequently reported diseases are diarrhoea, acute respiratory infections, skin diseases, pregnancy related complications, anaemia and malnutrition (GSS, 2005).

The most common chronic diseases are hypertension and diabetes (GSS, 2005)

\subsection{Out-Patient Department (OPD) Per Capita}

The proportion of persons visiting a health facility reflects the level of access of that centre to its catchment area in terms of OPD per capita. Normally, persons visiting health facilities are grouped by diseases, gender, and age and as well as patients who are insured and not insured by NHIS. These indicators are all determined from the collected data in the OPDs of the health facilities (clinics) to estimate the level of access of that facility to its clients.

The National Health Insurance since its introduction has led to increase in utilization of OPD services across all the regions (figure 1). The number of outpatients per capita continued increasing and in 2012 , the relative increase was $11 \%$. OPD per capita reached 1.17, more than doubling 2006 figure (Figure 2). Over $60 \%$ of those attending outpatient were females and overall women between the ages of 20 and 34 years were seen more often at the OPD than any other age group for males or females (Ministry of Health, 2013) .

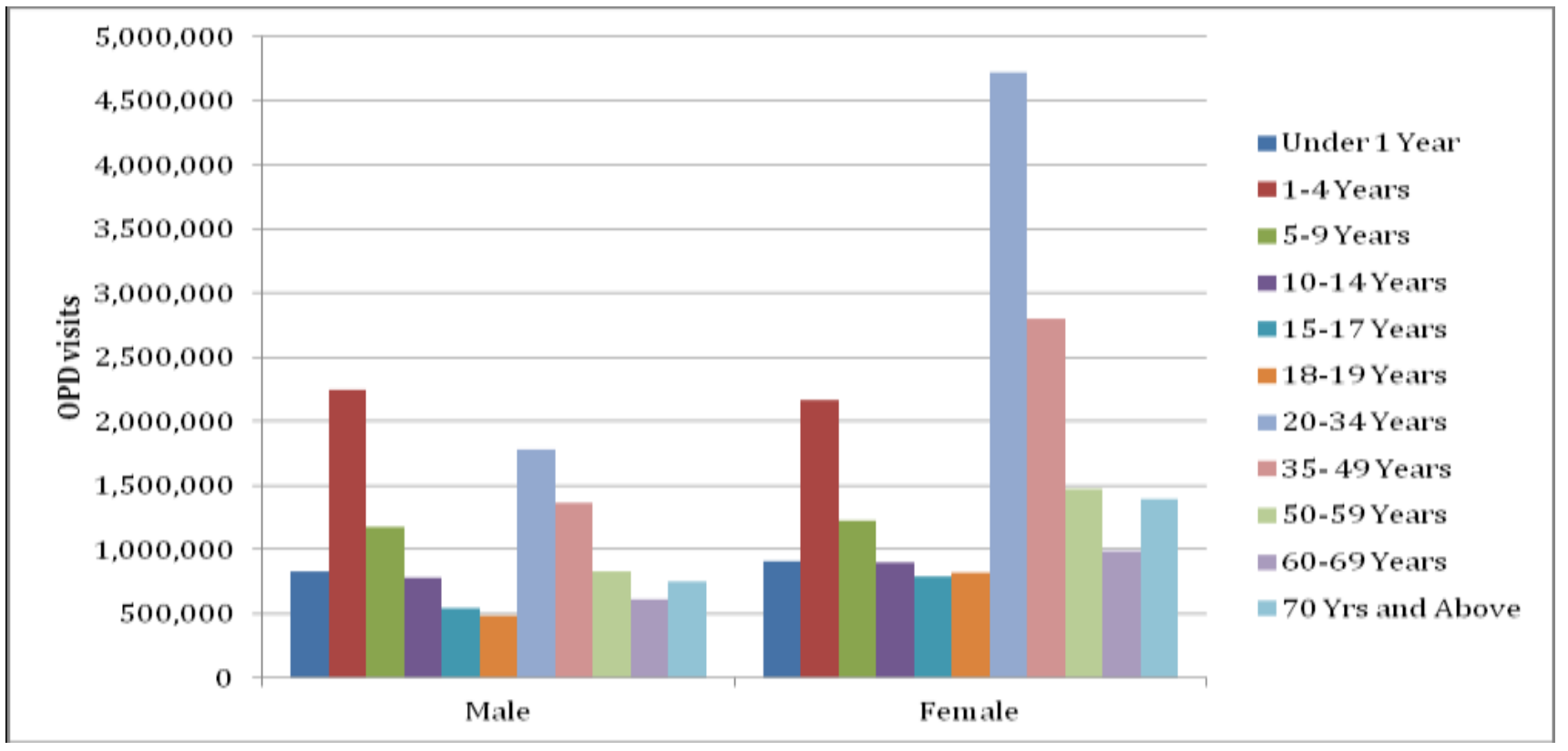

Figure 1 OPD visits by gender and age-group 2012, source GHS 


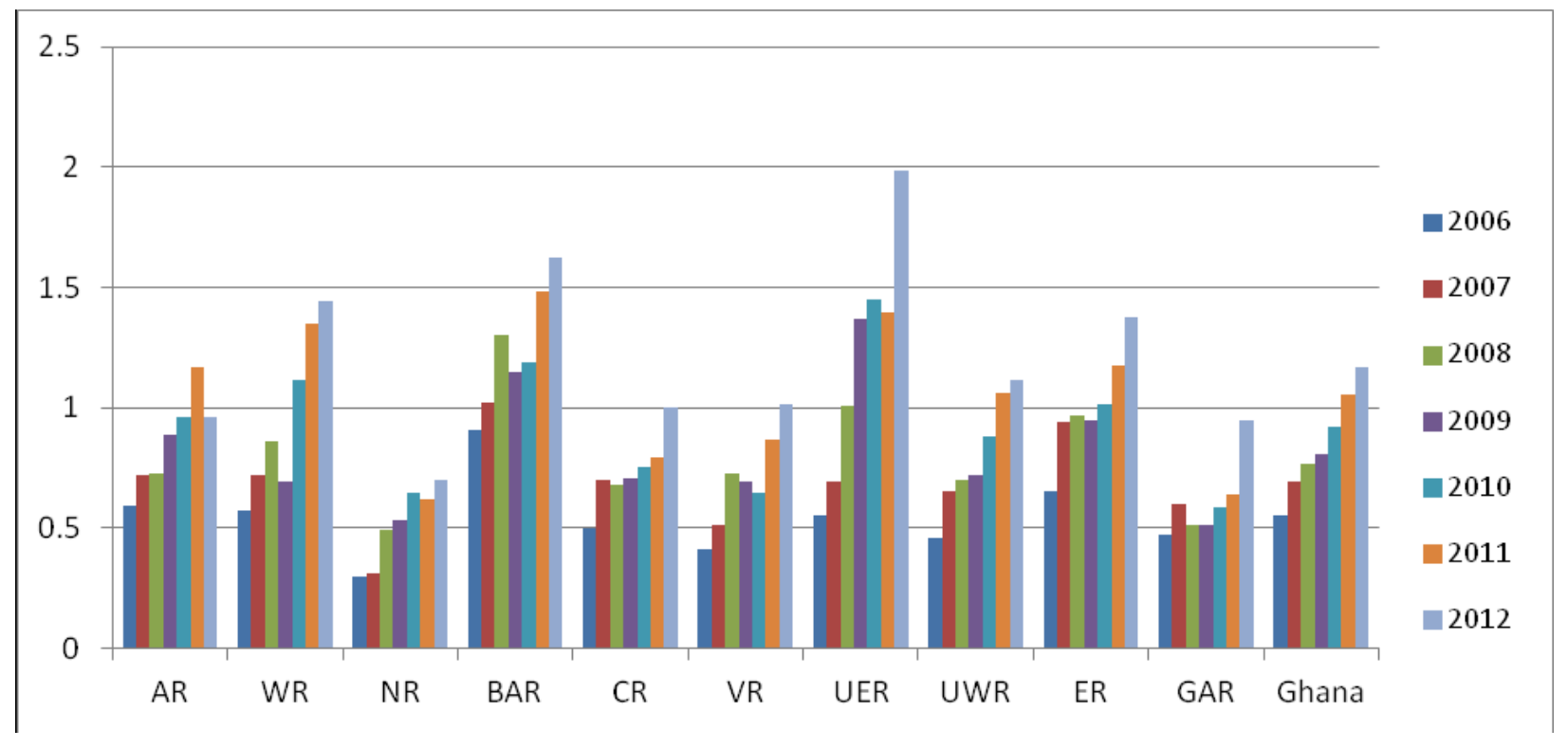

Figure 2: OPD per capita by region, 2006-2012, Source GHS

\subsection{Compilation of Clinical Access Indicators in Ghana Health Services}

At the end of each month, the consulting room registers are sent to the Public Health Units to compile the OPD and Morbidity reports. Each patient (entry) in the register is classified and counted according to the date, diseases, gender, age group, NHIS Insurance, case type (new or old), referral status. Malaria cases of children below five and above five are specially counted. Figure 3 shows a few entries in a consulting room register whilst figure 4 shows sample morbidity report.

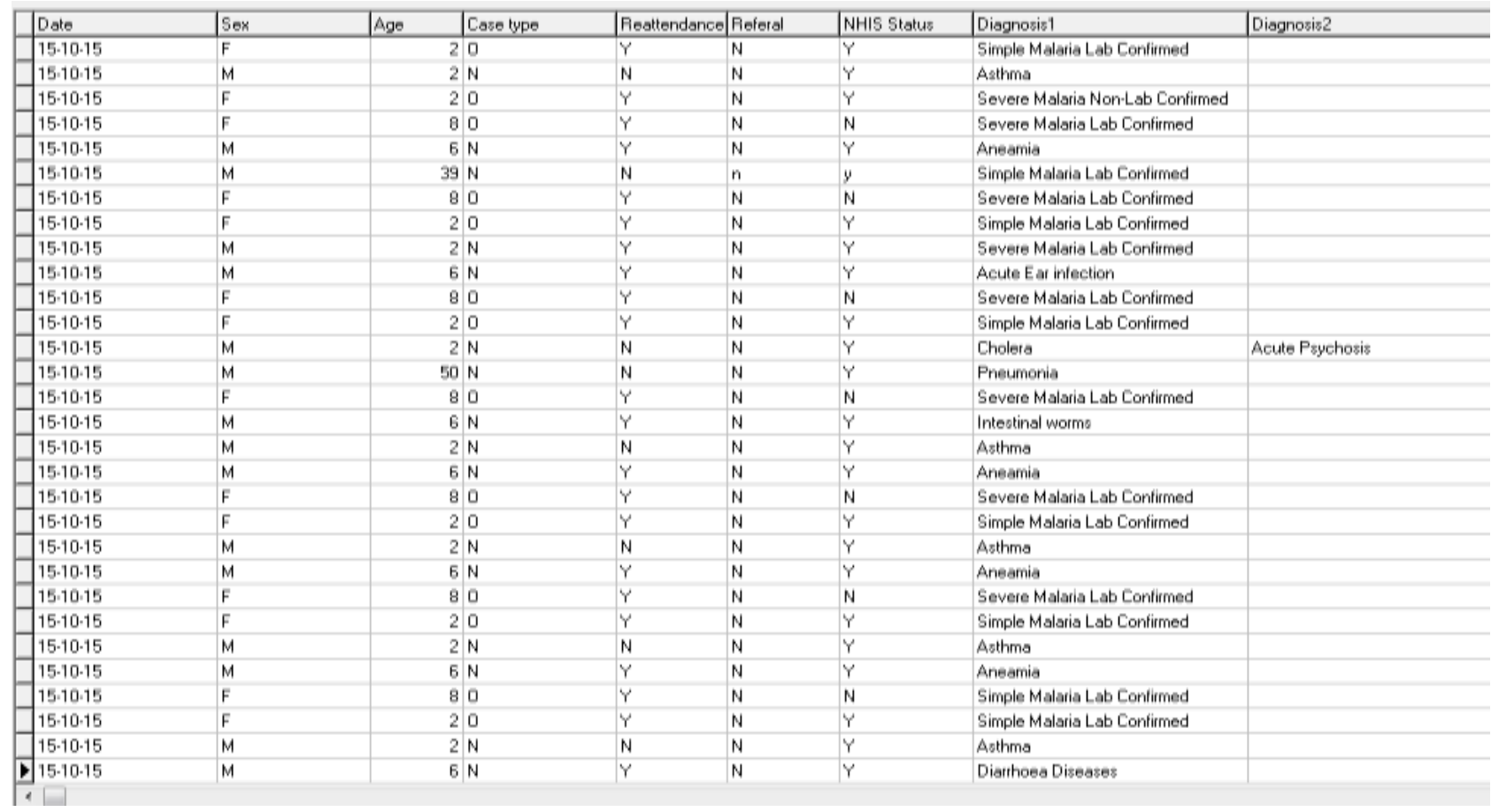

Figure 3 consulting room register sample 


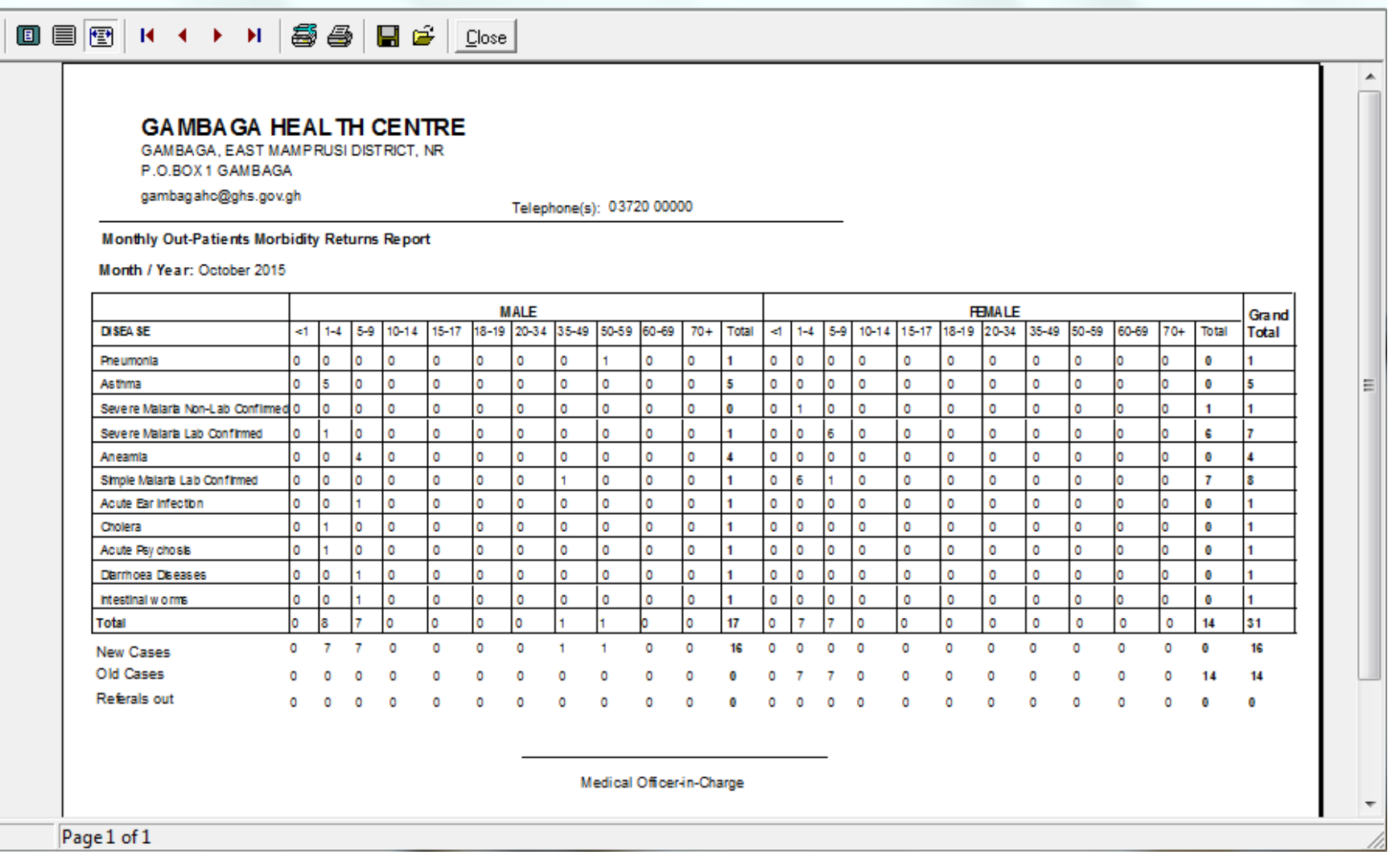

Figure 4 A sample morbidity reports

\subsection{Health Information Systems (HIS)}

Health Information Systems constitute the switch from conventional recordkeeping to computer-controlled systems in medical offices. In the Western countries, patient record keeping and management which were traditionally handled by medical assistants and health administrators resulting concentrated efforts on office procedures that generated paper records of patient data, payments, insurance claims, statistics etc. are now automated. Although paper-based systems aren't likely to disappear, many practices now have affordable Health Information Systems for scheduling, recording patient information, billing, filing insurance claims etc. (Sanderson, 2009).

Similar to other industries, the nature of healthcare industry has changed over time from a relatively stable industry to a dynamic one leading to health information systems evolving through several different technologies. The aim of Health Information Systems is to contribute to a high-quality and efficient patient care, disease control and prevention.

The current status of HIS varies among countries. There are 193 member countries of the World Health Organization (WHO). In 2009; 114 of them participated in the global survey on e-health (Muhammadi \& Mohd, 2011). Most developed countries have fully utilized HIS in their systems as they have the resources, expertise, and capital to implement them. However, in the developing countries, HIS have not been fully utilized yet according to WHO (2012). HIS are complex applications which have demonstrated benefits. Their complexity makes it imperative to have good application design, training, and implementation. Studies have evaluated Health Information Systems and reported on various benefits and limitations of these systems including increases in immunization rates, improved data collection, increased staff productivity, increased visitor satisfaction with services, improved communication, quality of care, access to data, reduced medical errors, and more efficient use of staff time (WHO, 2012).

\subsubsection{Health Information Systems in GHS}

Since 2005 Ghana has effectively implemented the National Health Insurance Scheme (NHIS) in all Districts/Municipalities/Metropolitans of the country. The NHIS strives to cover the entire population with equal universal access to the basic health services package. A key part of these health sector reforms is the need to develop better health information systems (Vital Wave Consulting, 2009).

In parallel with the NHIS implementation, the Ministry of Health $(\mathrm{MOH})$ initiated various programs to strengthen its inadequate health information system (HIS). As a responds, the MOH's Ghana Health Service (GHS) launched its automated system, called DHIMS. It attained full country coverage in 2007 after 
original piloting in 20 districts across the country (Vital Wave Consulting, 2009). Data flows are vertical, with accumulated data from health facilities in districts flowing to the regional and national levels. The GHS has expressed plans to extend it to the sub-districts where untapped capacity for data entry is present. DHIMS has faced numerous challenges, such as Inconsistent information requirements, lack of qualified information officers in many district hospitals, inadequate funding for deployment and poor equipment availability at the district level (Vital Wave Consulting, 2009)

\section{DESIGN OF THE SYSTEM}

It is often said that "if you fail to plan, you plan to fail" (GoodReads, 2011). Systems analyses and design are critical planning stages for effective information systems development and implementation. Advance software technologies are available to facilitate the development of health information system which resolves the data management challenges in data-centred organizations such as the hospitals. The traditional Software Development Life Cycle (SDLC) has been identified in the literature as the best practice strategy to develop both large and small scale data centred applications. At each step details of the activities carried out are captured.
Following the interviews conducted, it was well established that the problem was understood to be a data management challenge due to large volumes of data and the time-consuming processing requirements. The primary source of data for diseases surveillance, control and prevention in the GHS are the OPDs of hospitals, clinics and CHPS compounds. The details of patients' data captured and the processed reports are sampled in Figure 3 and 4.

The potential users were variously interviewed to ascertain the access levels, inputs, processing requirement and output reporting. We debriefed the Management of the Gambaga Health Centre on the project document which addressed the minimum requirements to create a solution to such a long standing problem. Management commitment, which is vital to systems development success and implementation, was guaranteed and as such the next steps in the SDLC were followed.

Funding and available ICT resources at the pilot site suggested we drew a conclusion on developing a client/server desktop application. A centralized database to store the OPD data was created in a relational database management system (figure 8)

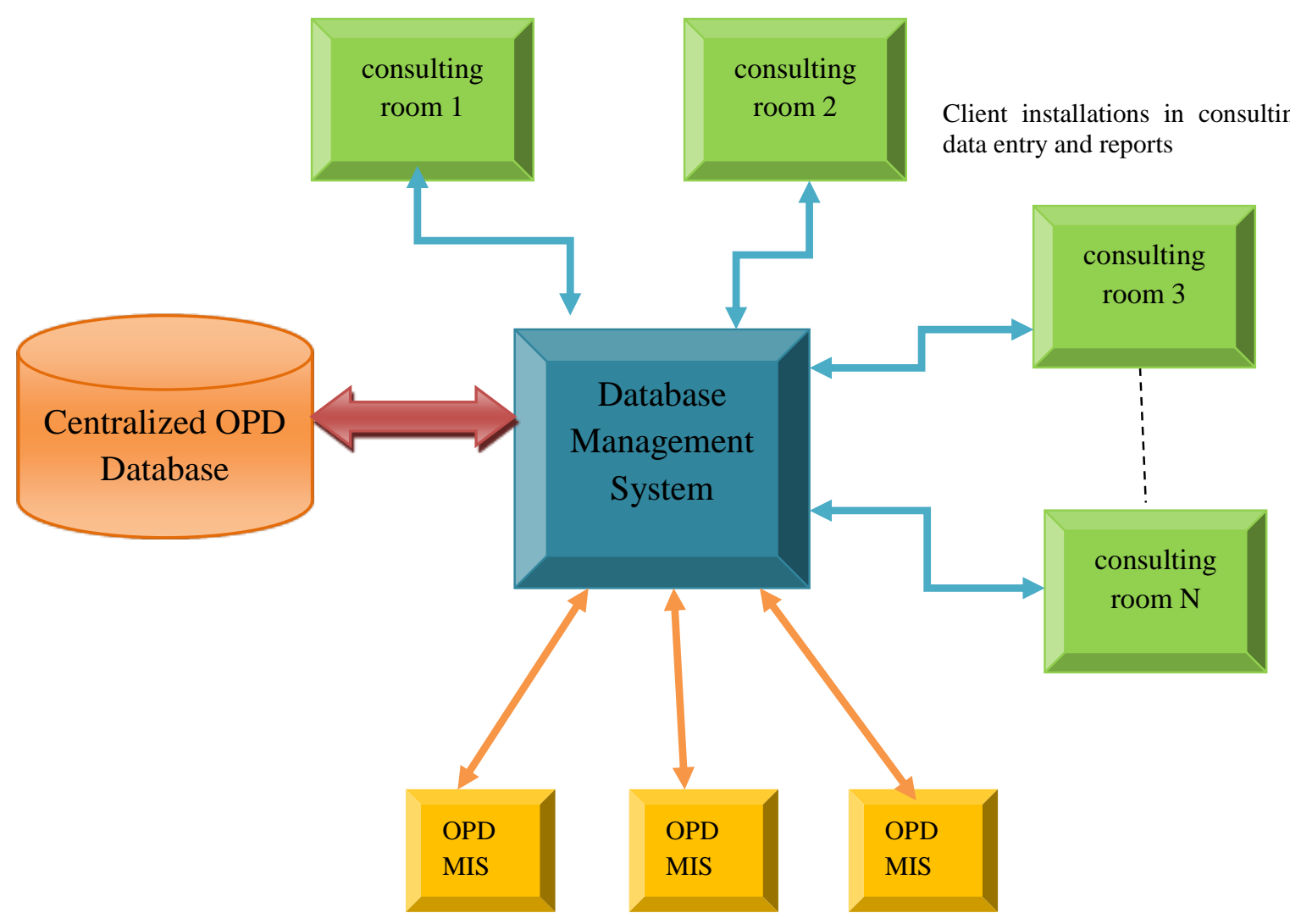

Client applications in offices that consume OPD MIS reports

Figure 5 Architecture of the solution 
The client side of the application is connected to the data server in a secured manner for data entry, processing and generation of the appropriate MIS reports (Figure 5). All users go through a login process to access the Information System. This architecture allows centralized but distributed database through the provision of a network environment. The complete system can equally be deployed on a standalone PC which will act as the server and the client at the same time.

The front and the back ends of the solution are distinctions which separate the user interface layer (presentation layer) and a data access layer respectively. The front-end code was written in Borland Delphi, an object oriented language which has a rich IDE for Rapid Application Developments (RAD). Code for creating graphical components are encapsulated and embedded in visual component libraries that make graphical and event driven applications easy to write.

Using the Data Manipulation Language (DML), the TransactSQL of the Microsoft SQL Server 2008, back-end interactions are done with the underlying data of the information system.

\section{SUMMARY OF FINDINGS}

Research methodologies vary from problem to problem. We have particularly used experimental research design in this work to manipulate some of the independent variables in order to observe the final results. A cross-sectional slice of public health nurses were experimented on manual compilation of the OPD and Morbidity reports of sampled attendance from the Gamabaga Health Centre for quantitative and qualitative analyses. Variables measured were limited to: Effect of years of work experience of a public health nurse on clinical access indicators compilation; Accuracy of the manual compilation; and effect of manual compilation on GHS deliverables.

\subsection{Effect of Years of Work Experience of a Public Health Nurse on Clinical Access Indicators Compilation}

Fifteen public health nurses with varying years experience from one to twenty worked on thirty patients records to measure these variables (Table 1 and 2). Some exclusive findings made included:

i. During the experimentation, it was realized that practitioners with five or more years in the job performed far better than the others (figure 9).

ii. Processing just thirty (30) patients, the average time used by the novice (one to four years experience) was about two hours (120 minutes) whilst the experience nurses used approximately one hour twenty three minutes ( 83 minutes). It implies that a facility attending to a minimum of 150 patients a day requires seven and half hours of an experienced public health nurse to come out with the morbidity reports for the day. Meanwhile the 2012 annual report of the GHS reveals that the public health nurses are not many in the country (GHS Annual report, 2012)

iii. It is also worth noting that from eight years experience, the Respondents used almost the same time. This implies that for the manual method to mature, a facility needs to have the public health nurses who are above seven years of experience.

Table 1: Years of work experience distribution of participants in the experiment

\begin{tabular}{|c|c|c|}
\hline Years experience & Frequency & Percent \\
\hline $0-1$ & 1 & 6.7 \\
\hline $2-4$ & 3 & 20.0 \\
\hline $5-8$ & 3 & 20.0 \\
\hline $9-12$ & 4 & 26.7 \\
\hline $13-15$ & 1 & 6.7 \\
\hline $15+$ & 3 & 20.0 \\
\hline Total & 15 & 100.0 \\
\hline
\end{tabular}

Table 2: Respondents' performance

\begin{tabular}{|c|c|c|}
\hline Respondent & $\begin{array}{c}\text { Years of work } \\
\text { experience }\end{array}$ & Time used \\
\hline Respondent \#01 & 12 & 81 \\
\hline Respondent \#02 & 10 & 83 \\
\hline Respondent \#03 & 13 & 80 \\
\hline Respondent \#04 & 6 & 84 \\
\hline Respondent \#05 & 1 & 135 \\
\hline Respondent \#06 & 4 & 111 \\
\hline Respondent \#07 & 2 & 80 \\
\hline Respondent \#08 & 3 & 110 \\
\hline Respondent \#09 & 8 & 85 \\
\hline Respondent \#10 & 16 & 81 \\
\hline Respondent \#11 & 5 & 90 \\
\hline Respondent \#12 & 2 & 120 \\
\hline Respondent \#13 & 9 & 80 \\
\hline Respondent \#14 & 19 & 79 \\
\hline Respondent \#15 & 10 & 80 \\
\hline
\end{tabular}




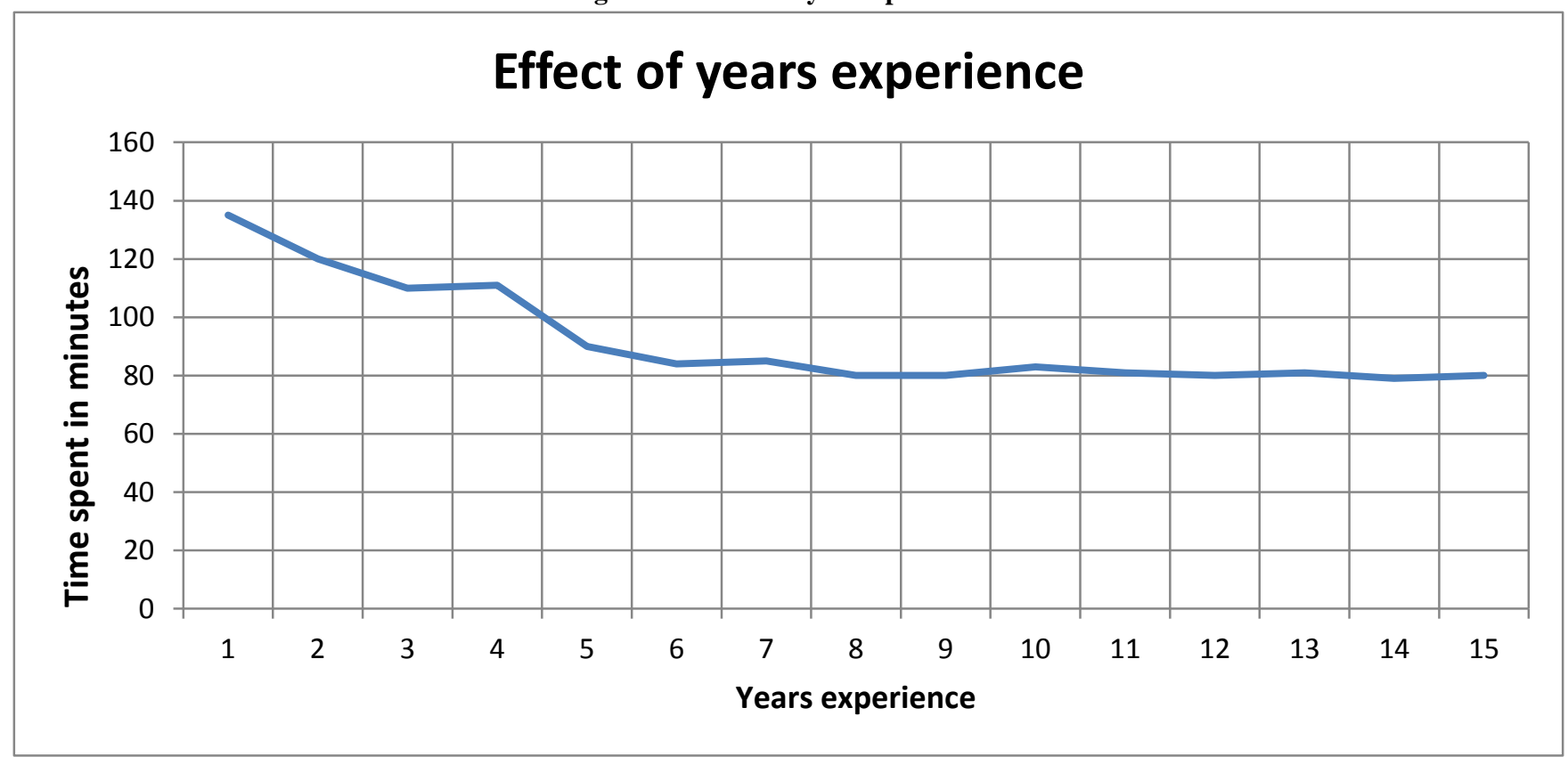

\subsection{Accuracy of the Manual Compilation}

Accuracy could not be established until simulations were done using the developed software. In general the experienced nurses had $85 \%$ accuracy whilst the others obtained $72 \%$.

\subsection{Effect of Manual Compilation on GHS Deliverables}

The effects of the manual compilations were obvious: The public health nurses will spend most of their duty hours in producing OPD morbidity reports if they really want accurate results. The ripple effect this situation is that the nurses are overburdened or overwhelmed in the discharge of their duties. The current remedy is that the GHS is striving to keep increasing the numerical strengths of public health nurses but salaries and wages budgetary constraints thwart this approach.

\section{SIMULATION RESULT ANALYSIS}

The sampled patients data used in the experiments were fed into the developed information system using a data entry clerk who had an average typing speed of $30 \mathrm{WPM}$. This is a very slow typist yet the data for thirty clients were entered in approximately seven minutes. Computation time on a standalone PC that met the minimum requirement for the thirty patients was in the range of two to five seconds! One can conclude that using the new Information System, the compilation time is reduced by $93 \%$.

\section{RECOMMENDATIONS AND FUTURE ENHANCEMENT}

The research findings suggest the following recommendations:

The Ghana Health Services and the Ministry of Health should linkup with the academia to research and produce vibrant, robust and inexpensive computing solutions to the various data management challenges currently inundating the sector.

The research results should be piloted in other health centres to finetune the information system for national implementation.

Special incentives should be given to individuals who accept postings to the deprived districts.

All health facilities should be empowered to use ICTs to enhance their data management processes since their industry is data-centred. 


\section{REFERENCES}

[1] Andries, J. d., \& Bob, B. (2008). The Changing Role of Human Resource Managers for International Assignments. International Review of Business Research Papers Vol.4.No.5. October-November2008, 166-181.

[2] Arif, M. (2015, March 1). The best software for small businesses (SMEs) - Essential Guide. Retrieved 3 15, 2015, from Tech Target Weekly Computer Magazine: http://www.computerweekly.com/feature/The-best-softwarefor-small-businesses-SMEs-Essential-Guide

[3] Erickson, T. (2002). Some problems with the notion of contextaware computing, ask not for whom the cell phone tolls. Communications of the ACM, vol. 45, no. 2 , 102-104.

[4] Ghana Health Service. (2006). Annual Report. Accra, Ghana: Ghana Health Service.

[5] Ghana Health Service. (2010). THE HEALTH SECTOR IN GHANA FACTS AND FIGURES. Accra: Ghana Health Services.

[6] Gregor, S., \& Jones, D. (2006). Improving the specification of Information Systems design theories, Working Paper,. The Australian National University.

[7] GSS. (2005). Ghana Demographic and Health Survey, Republic of Ghana. ACCRA: GSS.

[8] GSS. (2003). GSS, (2003), Core Welfare Indicator Questionnaire Survey, Republic of Ghana. ACCRA: GSS.

[9] Hall, D. (2003). Building a theoretical foundation for a learning-oriented management system. Journal of Information Technology Theory and Application, vol. 5, no. 2, 63-85.

[10] Haux, R. (2006). Health Information Systems - Past, Present, Future. International Journal of Medical Informatics , 268281.

[11] Haux, R. (2006). Health information systems - past, present, future. International Journal of Medical Informatics , 75, 26881.

[12] Laudon, K. C., \& Laudon, J. P. (2012). Management Information Systems, managing the digital firm, 12th Edition. New Jersey, USA: Pearson Education, Inc.

[13] Ministry of Health. (2006, November). Ghana Health Information System: National Level Review and Assessment Report. Retrieved February 15, 2015, from Ministry of Health Ghana Web site: http://www.mohghana.org/moh/docs/hmn_act/National\%20HIS\%20Assessme nt\%20Report.doc

[14] Ministry of Health. (1996). Ghana Health Sector: Facts and figures. Accra, Ghana: Ministry of Health.
[15] Ministry of Health. (2013). Holistic Assessment of the Health Sector Programme of Work 2012. Accra, Ghana: Ministry of Health.

[16] Muhammadi, A., \& Mohd, N. A. (2011). "Evaluating CRM Implementation in Healthcare Organization”. International Conference on Economics and Business Information (pp. 1-5). Bangkok, Thailand: IACSIT Press.

[17] Nonna, R. (1979). Managing The Crisis In Data Processing. Harvard Business Review 57 (2) , 115-126.

[18] Paolo, L., Nicola, R., Luca, G., \& Mariano, C. (n.d.). Health Care Information Systems: Architectural Models and Governance. Milano, Italy: Fondazione Politecnico di Milano and IHCO.

[19] Sanderson, S. M. (2009). Computers in the Medical Office (6th Edition). New York: McGraw-Hill.

[20] Silberschatz, A., Henry, K., \& S, S. (2011). Database System Concepts Sixth Edition. NY, USA: McGraw-Hill.

[21] Stair, R. M., \& Reynolds, G. W. (2010). Principles of Information Systems (9th Edition). Boston, USA: CENGAGE Learning.

[22] Subhash, V. (2008, October). GNotice: Limitations of Web Applications. Retrieved February 10, 2015, from GNotice Web site:

http://www.gnostice.com/nl_article.asp?id=145\&t=Limitation s_of_Web_Applications

[23] Terry, Q. (2001). Introduction to the Unified Modeling Language. Rational Developer Network , 5-7.

[24] Vital Wave Consulting. (2009). Health Information Systems in Developing Countries,A Landscape Analysis. Vital Wave Consulting.

[25] WHO. (2010). Health financing and access to effective interventions, World Health Report (2010), Background Paper, 8. Geneva: World Health Organization.

[26] WHO. (2012). Management of patient information: trends and challenges in Member States: based on the findings of the second global survey on eHealth. Switzerland: World Health Organization.

[27] WHO. (2000). The World Health Report 2000: Health Systems: Improving Performance. Geneva: World Health Organization.

[28] WHO. (2011, March). World Health Organization. Retrieved February 16, 2015, from World Health Organization Publications: http://www.who.int/goe/publications/en

[29] WIKIPEDIA FREE ENCYCLOPEDIA. (1996). Front and back ends. Retrieved February 20, 2015, from Wikipedia web site: http://en.wikipedia.org/wiki/Front_and_back_ends 